\title{
Justiça a Serviço da Paz: Um estudo sobre a efetividade do Tribunal Penal Internacional para Antiga lugoslávia em seu papel como agente no processo de reconciliação na região
}

\author{
Beatriz Ribeiro Carvalho ${ }^{1^{*}}$
}

\begin{abstract}
Resumo:
O presente artigo busca analisar o impacto do Tribunal Internacional para a Antiga Iugoslávia (ICTY) no processo de reconciliação entre sérvios, bósnios e croatas no contexto das guerras de independência na Iugoslávia. Argumenta-se que o tribunal assume um papel de protagonismo nesse processo, em um movimento que vai além de suas capacidades formais. Ademais, posteriormente se comprova, por meio de exemplos pontuais e uma análise do contexto da região após o fim das atividades da Corte, que esse projeto inicial não é reproduzido na prática. As decisões do Tribunal, devido a sua própria natureza, são passíveis de mobilização pelos grupos a favor de narrativas excludentes sobre os eventos. Dessa forma, mina-se a confiança das populações na capacidade arbitrária do tribunal e resulta-se em consequências prejudiciais ao processo de construção de paz na região.
\end{abstract}

Palavras-chave: Direito Penal Internacional; ICTY; Reconciliação; Pós-conflito.

\begin{abstract}
:
The present work aims to analyze the impact of the International Criminal Tribunal for the Former Yugoslavia (ICTY) in the reconciliation process between Servs, Bosnians and Croats in the context of the wars of Independence in Yugoslavia. It is argued that the court takes the role of protagonist in this process, a move that goes inherently beyond its formal capabilities. Furthermore, it is proven that this initial project does not employ specific examples and environmental analysis of the region after the end of the tribunal's activities. Thanks to their nature, the groups in favor of excluding narratives about the events can mobilize the tribunal's decisions. Therefore, the populations' confidence regarding the tribunal's judging capability is undermined, impairs the region's peacebuilding process.
\end{abstract}

Keywords: Peacebuilding; International Criminal Law; ICTY; Reconciliation.

\footnotetext{
1* Graduação em Relações Internacionais pela PUC-Rio, em dezembro de 2019, com Domínio Adicional em Comércio e Negócios Internacionais. Este trabalho é o resultado da pesquisa ganhadora do Prêmio Gerson Moura do IRI/PUCRio como melhor trabalho de conclusão de curso no eixo de Conflitos Internacionais. E-mail: bia.r.carvalho.25@gmail.com.
} 


\section{Introdução}

O Tribunal Penal Internacional para a Antiga Iugoslávia (ICTY), estabelecido em 1993, foi um marco para o desenvolvimento do Direito Internacional Penal e da justiça de transição. A experiência da corte foi formativa para o subsequente Tribunal Penal Internacional e para uma série de doutrinas e paradigmas presentes hoje na prática do direito internacional e na construção de paz, em especial no que é referente a processos de reconciliação.

O presente artigo busca analisar o impacto do estabelecimento e atividades do ICTY para o processo de reconciliação no território da antiga Iugoslávia, fazendo um corte geográfico e temporal específico que coloca como objeto de estudo apenas os eventos referentes às guerras na Croácia e na Bósnia e Herzegovina. O objetivo da análise é mostrar como o tribunal se insere no processo de reconciliação da sociedade pós-guerra e acaba por tomar para si um papel de protagonista nele. Isso se dá a partir de uma convicção na capacidade dos processos adjudicatórios de promover um movimento reconciliatório. Dessa forma, torna-se aceitável e até mesmo necessário que se analise o sucesso (ou ausência de) do tribunal em atender a essas expectativas.

Para tanto, a argumentação se divide em três partes. Primeiro, promove-se uma breve revisão histórica da Iugoslávia e dos conflitos que se propagaram por seu território na década de 90 . Além disso, também é exposto nessa seção as narrativas que nascem dos conflitos, caracterizadas pelas suas diferenças no que diz respeito aos acontecimentos e motivações da guerra. Dessa forma, pretende-se contextualizar o conflito no qual e para qual o ICTY se forma, de maneira a entender o peso da reconciliação que se busca alcançar ao fim dele, bem como apresentar os grupos envolvidos.

A seguir, o foco se torna o próprio ICTY: nessa seção, promove-se primeiro uma revisão da evolução do Direito Internacional Penal, empregando para isso a teoria de Kathryn Sikkink (2011). Particularmente, observa-se a intenção e a necessidade de se afastar da "justiça dos vencedores" praticada anteriormente. Esse ponto é importante pois são justamente as acusações de decisões parciais e políticas que acabam por minar a confiança das populações na arbitragem do tribunal. Entender o processo de formação do tribunal é importante para conseguir entender de onde surgem parte das suas expectativas e limitações

Por fim, a análise aponta o papel de protagonista que o tribunal assumiu no processo de reconciliação e, consequentemente, na construção de paz nos Estados que constituíram a Iugoslávia. A partir disso, busca-se demonstrar de que forma o tribunal perde a confiança das populações envolvidas e falha nessa missão. Para isso, utiliza-se de dois casos específicos, como exemplos de decisões marcantes que acabaram por criar divergências entre os grupos e as narrativas que eles defendem. É explorado a reação nos países face a essas decisões e argumenta-se que elas terminaram por inflamar discursos nacionalistas e prejudicar qualquer avanço ou esforço em direção a reconciliação. $O$ trabalho conclui com uma análise do ambiente político e social dos países em questão atualmente, incluindo apresentação de resultados de pesquisas recentes, para mais uma vez demonstrar a falência da reconciliação e a perpetuação das mesmas tensões que o ICTY havia tentado ao menos contribuir para a solução. 


\section{lugoslávia: início e fim}

\section{i. a unificação da lugoslávia}

O primeiro Estado iugoslavo surge em 1918, no chamado Reino dos Sérvios, Croatas e Eslovenos. O próprio nome do país já expõe a sua principal característica, que viria a definir a federação que se seguiria ao reino, bem como a guerra que a desmantelaria. A existência da Iugoslávia se baseava na noção de uma identidade em comum que uniria os grupos identitários que já existiam, até então de forma separada, na região. Dessa forma, esses grupos utilizam o seu direito à autodeterminação para se governar de forma compartilhada (BACKER, 2015, p. 7).

A história dos grupos, que juntos formariam os chamados eslavos do sul, é extensa: eles teriam chegado na região que viriam a ocupar entre os séculos VI e VIII A.C. e desde então mantido, de alguma forma, sua presença na região. Institucionalmente, no entanto, a autonomia dos grupos enfrenta desafios, como a incorporação do reino da Croácia pela Hungria em 1102 e dos reinos da Sérvia e da Bósnia pelo Império Otomano a partir de 1459. Apesar disso, os grupos chegam no século XIX com alguma percepção de identidade, que passa a ser explorada quando os principais poderes políticos da região, os impérios Habsburgo e Otomano, começam a declinar, permitindo que a independência se torne uma alternativa viável (BACKER, 2015, p. 8-14).

A Formação do Reino da Iugoslávia, no entanto, só ocorre no fim da Primeira Guerra Mundial, quando a extinção da Áustria-Hungria abre espaço para a independência de vários movimentos nacionalistas que existiam em seu território. Em 29 de outubro de 1918, se forma o Estado de Eslovenos, Croatas e Sérvios, que se unifica com o Reino da Sérvia em 1 de dezembro, formando a primeira versão da Iugoslávia. A transformação do Reino da Iugoslávia para o segundo modelo de estrutura, aquele que se mantém de pé até o fim da federação, se dá a partir da Segunda Guerra Mundial (BACKER, 2015, p. 1419).

\section{ii. República Socialista Federativa da lugoslávia}

A Iugoslávia foi invadida pelo Eixo em 1941, durante a Segunda Guerra. Como consequência direta disso, os anos que se seguiram foram marcados por uma disputa de poder entre lideranças políticas que surgiram como oposição. Entre elas estava a que viria a tomar controle do país, os Partisans, liderados por Josip Broz Tito. Os partisans conseguiram retornar controle sobre os territórios dominados e estabeleceram neles um modelo comunista federalista. Na nova república iugoslava existiam seis federações: Eslovênia, Croácia, Montenegro, Macedônia, Bósnia e Herzegovina e Sérvia (ZEJNULLAHI, 2014, p. 1). Dessas, apenas a Bósnia não representava diretamente um povo da região. Ao invés disso, ela seria constituída pela união de sérvios, croatas e mulçumanos.

Tito conseguiu utilizar da narrativa heroica criada em volta do seu papel na liberação da Iugoslávia para construir uma noção de nação baseada na multinacionalidade da classe trabalhadora. Porém, a morte de Tito, em 1980, deixou o país sem liderança 
política e simbólica de peso, abrindo caminho para uma série de conflitos que culminariam nas guerras da década de 1990 (ZEJNULLAHI, 2014, p. 19-39).

\section{iii. As Guerras de 1990s}

O início do desmantelamento do Estado iugoslavo pode ser considerado como o congresso da Liga de Comunistas da Iugoslávia (SKJ) de 1990. Em meio a um cenário internacional marcado por mudanças sistêmicas onde a proeminência da ideologia comunista perdia cada vez mais força, a Eslovênia liderou o movimento interno ao pedir por mudanças no sistema doméstico (ZEJNULLAHI, 2014, p. 38). Do outro lado do espectro, no mesmo momento, o controle do partido sérvio era assumido por Slobodan Milosevic. As escolhas políticas dele e a influência que elas tiveram nos eventos que se seguiram foram alvos de inúmeras análises posteriores, mas é indubitável que Milosevic foi um dos grandes personagens dos acontecimentos que se seguiram.

Até 1990, Milosevic já havia apoiado movimentos de grupos étnicos sérvios dentro de Vojvodina e Kosovo, e revogado o status dessas regiões de comunidades autônomas (ZEJNULLAHI, 2014, p. 36). No Congresso da Liga Comunista, a delegação eslovena creditou à oposição dele o fracasso de suas propostas. Outro ponto decisório do congresso é o apoio dado pela delegação croata à Eslovênia. O surgimento desse alinhamento entre as duas federações insinua o porquê de elas terem sido as primeiras a declarar independência, em junho de 1991.

A oposição de Milosevic a essas declarações residia na noção de que a criação desses Estados seria uma violação do direito de autodeterminação dos sérvios que viviam nesses territórios. A situação era muito mais grave na Croácia do que na Eslovênia, onde apenas $14 \%$ da população se identificava com qualquer outra etnia que não a eslovena (BENDERLY \& KRAFT, 1994, p. 288). Na Croácia, apenas 78\% da população era croata e 12\% se diziam especificamente sérvios (RAMET, 2016, p. 311). Essa tensão específica era potencializada pela existência de um partido sérvio na Croácia (BACKER, 2015, p. 41). Dessa forma, faz sentido que o conflito armado na Croácia tenha sido muito mais prolongado do que na Eslovênia.

Forças militares da JNA, as forças armadas da Iugoslávia, fortemente ligadas à Sérvia, se mobilizaram contra as duas independências imediatamente após suas declarações, no dia 25 junho. No entanto, a intervenção no território esloveno se encerrou dez dias depois, graças a uma negociação liderada pela Comunidade Europeia. Já o conflito na Croácia se estendeu até agosto de 1995, se tornando então contemporânea e correlacionada à guerra na Bósnia e Herzegovina.

O conflito na Bósnia é entendido por alguns como inevitável dado a constituição multiétnica e multirreligiosa do país (GLENNY, 1996, p. 144). De fato, a natureza estrutural do país, composta por sérvios ortodoxos, croatas católicos e bósnios mulçumanos foi um fator decisivo na eclosão do conflito. Embora governassem o país em coalizão, os partidos representantes desses três grupos entram em crescente discordância conforme a guerra ocorria na região ao seu redor. Logo, o partido sérvio declarou independência do território que controlava, fato que ocorreu também, quase que paralelamente. Ele foi seguido pelo partido croata no ano seguinte e episódios de violência se tornaram frequentes. Um conflito entre os três grupos, com os partidos croatas e sérvio tendo amplo apoio dos respectivos Estados, e alto grau de violência caracterizaram a guerra.

As duas guerras só terminaram com a assinatura do Acordo de Paz de Dayton, em novembro de 1995. Até sua assinatura, a região da Iugoslávia foi palco de inúmeras violações de Direitos Humanos e Direito Humanitário. Mecanismos de limpeza étnica 
foram amplamente usados (NAÇÕES UNIDAS, 1995, p. 65-66) e um dos maiores episódios de violência, o Massacre de Srebrenica, ilustra a perpetração de genocídio (CORTE INTERNACIONAL DE JUSTIÇA, 2007, p. 132). Na ocasião, cerca de 8.000 homens e meninos foram assassinados por forças sérvias na cidade de Srebrenica, na Bósnia e Herzegovina.

\section{iv. O Pós-Guerra: reconciliação}

O Acordo de Dayton, além de colocar fim no conflito armado, também foi responsável por determinar a organização política da região no pós-guerra. Com a Sérvia e a Croácia já reconhecidas internacionalmente, o Estado da Bósnia e Herzegovina foi determinado como sendo formado por duas entidades autônomas: a Federação e a República Srpska (Dayton Agreement, 1995). Ambas são fortemente guiadas pelas divisões étnicas que marcaram a guerra, com a República Srpska ocupando o território da área da Bósnia que continha a população sérvia e havia declarado sua independência no início do conflito (BACKER, 2015, p. 77), adotando inclusive o mesmo nome que viria a ter agora sob o estado da Bósnia e Herzegovina. A perpetuação institucional das divisões étnicas no pós-guerra permitiu que movimentos nacionalistas as explorassem (HAIDER, 2009, p. 110) e agiu como um dificultador no processo de reconciliação, uma vez que não criava incentivos para cooperação ou sequer interação entre os grupos (SUBOTIC, 2009, p. 368). Apesar disso, o Acordo conseguiu de maneira factual pôr um fim na agressão e começar a criar condições para o estabelecimento da paz (NOGUEIRA, 2000, p. 145).

O que o Acordo de Dayton não resolve, no entanto, são as diferenças narrativas sobre todo o conflito. Mesmo após o seu fim, a guerra foi marcada por divergências sobre suas supostas motivações e acontecimentos propriamente ditos. Na Croácia, ela é entendida como uma guerra pela independência e as ações dos soldados croatas são aceitas e até mesmo defendidas. Na Sérvia, o consenso é que a luta se deu frente à ameaça à sobrevivência dos povos sérvios que viviam em territórios anexos. Já na Bósnia a narrativa varia entre os grupos que constituem a população do país. O estabelecimento de uma narrativa oficial sobre os conflitos era tarefa urgente que precisava ser cumprida para que qualquer futuro estável na região se tornasse possível. Como a seguir, essa incumbência caiu sobre o Tribunal Penal Internacional para a Antiga Iugoslávia, fato que contribuirá tanto para determinar seu papel importante na reconciliação, quanto sua limitação no alcance dele.

\section{O ICTY: passado e futuro}

\section{i. Direito International Penal: Justice Cascade}

No intuito de localizar o ICTY dentro do desenvolvimento da justiça de transição e do direito penal internacional, empregaremos a teoria desenvolvida por Kathryn Sikkink, em seu livro "The Justice Cascade" (2011). Essa tentativa permite entender o tribunal como parte de um movimento contínuo, e assim compreender de forma mais 
integral seus marcos e feitos.

Kathryn Sikkink argumenta que o Direito Internacional Penal como o entendemos hoje surge de um movimento de "cascata". Esse tipo de denominação é utilizada para descrever fenômenos que marcam uma incipiente mudança de paradigma, a partir da ideia inicial ou, em outras palavras, stream, e ganha apoio de forma inesperada até atingir um "ponto de virada" e se firmar como um novo paradigma. O ponto de virada marca o momento em que uma porção essencial dos atores envolvidos adota a prática em questão.

O fenômeno específico, que dá título ao livro, aponta para uma mudança no paradigma de accountability, que ela define como práticas onde a ação de atores é regida como um conjunto de normativas e mecanismos de penalização, caso essas normas sejam descumpridas. Para auxiliar na ilustração desse processo, a autora propõe três modelos de accountability: o modelo de impunidade, o modelo de accountability estatal e o modelo de accountability individual. É importante notar que os modelos aqui citados não se substituem progressivamente ao longo do tempo, ao invés disso, eles se somam. Dessa forma, os três ainda se fazem presentes, em diferentes formas, na realidade atual.

Seguindo a lógica do argumento da autora, anteriormente à Segunda Guerra Mundial, o paradigma reinante era aquele da impunidade. Nele, era entendido que indivíduos ligados ao governo estariam isentos de qualquer acusação ou julgamento ligados a violações de direitos humanos. A mudança se inicia após a Segunda Guerra Mundial, quando o choque público mundial com as violações no holocausto foi forte suficiente para alterar a ótica dominante, criando o sentimento de necessidade de responsabilização. Esse seria o ponto de partida para o estabelecimento dos Tribunais de Nuremberg e Tóquio, iniciando um novo stream.

Dessa forma, o ICTY tem nos tribunais de Nuremberg e Tóquio seus principais antecedentes e fonte de jurisdição. A importância desses exemplos para a formulação do ICTY é resumida por Sikkink:

A maioria dos indivíduos envolvidos na criação do ICTY cita os Tribunais de Nuremberg, os Tribunais de Crimes de Guerra de Tóquio e, em uma extensão muito menor, o julgamento de Eichmann em Israel, como os principais precedentes para seu trabalho (SIKKING, 2011, tradução nossa) ${ }^{2}$.

\section{ii. Os Tribunais de Nuremberg e Tóquio}

O tribunal de Nuremberg surge no pós-Segunda Guerra Mundial a partir do estabelecimento do Estatuto do Tribunal Militar Internacional, ou Carta de Londres, em 8 de agosto de 1945. A Carta é assinada pelos países que constituíam as quatro grandes potências vencedoras da guerra: Estados Unidos, Reino Unido, França e União Soviética (HAGAN, 2003, p. 21-23; CRYER et al., 2011, p. 111). O primeiro ponto de importância

\footnotetext{
${ }^{2}$ No original: "Most individuals involved in the creation of the ICTY cite the Nuremberg Tribunals, the Tokyo War Crimes Tribunals, and to a much lesser extent, the trial of Eichmann in Israel, as the main precedents for their work".
} 
de Nuremberg é, logo, sua própria existência. Sheldon Glueck, professor de direito em Harvard e defensor da criação do Tribunal, defendeu a sua necessidade afirmando que ele foi "um símbolo concreto da determinação dos povos civilizados em reivindicar o Estado de Direito nas relações internacionais" (GLUECK apud HAGAN, 2003, p. 22) ${ }^{3}$. O tribunal julgou vinte e quatro indivíduos por associação criminosa, crimes de guerra, crimes contra a paz e crimes contra a humanidade

Seu tribunal irmão, o Tribunal Militar Internacional para o Extremo Oriente, conhecido como Tribunal de Tóquio, foi estabelecido em janeiro de 1946, com base na Declaração de Potsdam, documento que afirma as exigências dos Estados Unidos, China e Reino Unido para a rendição do Japão. O documento, aceito pelo governo japonês após os ataques de Hiroshima e Nagasaki, continha em seu ponto 10 a intenção de levar criminosos de guerra à justiça (CRYER et al., 2011, p. 116).

Sendo assim, os dois tribunais são pontos importantes para a evolução da justiça internacional penal, pois criam a possibilidade concreta da criminalização individual por crimes contra a paz, contra a humanidade e crimes de guerra (HAGAN, 2003, p. 24; CRYER et al., 2011, p. 113; FOLEY, 2017, p. 23). No entanto, ambos os julgamentos enfrentaram uma crítica essencial, que se torna especialmente importante para entender certos acontecimentos durante o ICTY que são base para o argumento apresentado.

O Tribunal de Nuremberg e o Tribunal de Tóquio são entendidos como exemplos de justiça dos vencedores (CRYER et al., 2011, p. 113-118). O termo é usado para denominar processos jurídicos marcados por injustiças, promovidos pelo lado vencedor de um conflito. Isso significa que a justiça se torna um mecanismo parcial de fazer político. Em relação aos casos em questão, é possível ligar esse argumento a uma série de características básicas da estrutura dos tribunais. Em ambos, tanto os juízes quantos os promotores eram nacionais dos países que formavam a aliança vencedora e nenhuma acusação contra indivíduos dos Estados vencedores foi levada à corte (CRYER et al., 2011, p. 111-118). Essencialmente, os tribunais foram mecanismos impostos pelos vencedores sobre os perdedores e seu desenvolvimento ocorreu com uma ideia prévia de qual objetivo se buscava atingir.

Alguns argumentam que embora falha, a justiça dos tribunais era necessária e inovadora. Glueck afirma que "nas fases iniciais de qualquer sistema de lei, o executivo

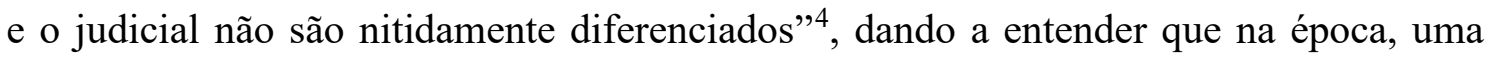
justiça neutra não seria uma possibilidade viável (GLUECK apud HAGAN, 2003, p. 22). No entanto, superar a justiça dos vencedores foi algo que o ICTY precisava e efetivamente buscou alcançar.

\section{iii. O Estabelecimento do ICTY}

\footnotetext{
${ }^{3}$ No original: "a concrete token of the determination of civilized peoples to vindicate the rule of law in international affairs".

${ }^{4}$ No original: "in the early stages of any system of law the executive and the judicial are not sharply differentiated".
} 
A ligação da corte ad hoc com Nuremberg, em particular, é clara e prática desde o momento que surge a ideia de um tribunal internacional para a região. A primeira vez que essa noção aparece é por meio de um jornalista croata, Mirko Klarin, em uma reportagem publicada em maio de 1991 e intitulada "Nuremberg Now!" [Nuremberg agora!] (SIKKINK, 2011, p. 111; BACKER, 2015, p. 99). As organizações não governamentais, em especial a Human Rights Watch (HRW), que permaneciam na região e configuravam importante fonte de relatórios sobre a situação da guerra, seguiram-se a Klarin no pedido por uma corte internacional. Posteriormente, o cofundador da HRW, Aryeh Neier, escreveria que a ideia era de fato a formação de um tribunal similar ao responsável por julgar nazistas, com o objetivo de tratar de crimes similares aqueles cometidos por aqueles. Ele descreve essa comparação como natural (NEIER, 1998, p. 120). De fato, a subsequente divulgação de imagens da guerra na mídia ao redor do mundo comprovou que essa naturalidade era compartilhada pelo público geral. As imagens de campos de concentração nos Balcãs evocaram a memória coletiva sobre o holocausto e causaram um sentimento de indignação pública em muitos países membros da ONU (CRYER et al., 2011, p. 123; BACKER, 2015, p. 99).

Sendo assim, o Tribunal Penal Internacional para a Antiga Iugoslávia é estabelecido pela resolução 827 do Conselho de Segurança das Nações Unidas, em 25 de maio de 1993. Antes disso, a crescente demanda por ação internacional no conflito já havia feito com que o Conselho instituísse, em agosto de 1992, uma comissão de especialistas para investigar violações do Direito Humanitário Internacional na região. O primeiro relatório intercalar da comissão, datado de 9 de fevereiro de 1993, prenuncia o tribunal ao afirmar que sua criação estaria de acordo com a direção das investigações (POCAR, 2008). A adoção pelo conselho de segurança deste relatório agia como resposta oficial da organização para a situação, permitindo que a pressão por intervenção fosse aliviada, ao mesmo tempo que evitava a ação militar no conflito (FOLEY, 2015, p. 179; BACKER, 2015, p. 99). Isso era significativo pois, apesar da pressão popular, líderes importantes, como o presidente americano George H. W. Bush e o primeiro-ministro britânico John Major tinham interesses políticos, sejam eles de ordem doméstica ou de política externa, de evitar o ingresso prático no conflito (HAGAN, 2003, p. 36).

A resolução ${ }^{\circ} 827$ cria ICTY sob o capítulo VII da Carta da ONU, que trata de ações relativas à ameaça à paz, ruptura da paz, e atos de agressão. A resolução estabeleceu um regime de cooperação mandatório a seus membros e aprovou o Estatuto do Tribunal Internacional. $\mathrm{O}$ estatuto dá ao tribunal jurisdição sobre crimes de guerra, crimes contra a humanidade e genocídio cometidos no território da antiga Iugoslávia a partir do início do ano de 1991. No mais, ele também estabelece a organização estrutural do ICTY (NAÇÕES UNIDAS, 2009, p.5-7).

O processo decisório do tribunal é feito por três câmaras de julgamento, formadas por três juízes e responsáveis pelo primeiro parecer, e a câmara de apelações, que dá o veredito final caso exista recurso por parte da defesa (CRYER et al., 2011, p.124). A existência da câmara de apelações possibilita a reversão completa da primeira decisão, alternativa que é ponto de partida para uma série de decisões polêmicas que são exploradas em seções seguintes. 
Apesar de estabelecido em 1993, o ICTY começou seu primeiro julgamento apenas em 1996, quando o Acordo de Dayton já havia sido assinado. Dessa forma, o impacto do tribunal da resolução do conflito foi praticamente nulo, uma vez que não agiu como impeditivo para o prosseguimento do conflito e das violações de direitos que nele ocorriam (MILANOVIC, 2016, p.234; TRBOVC \& PETROVIC, 2017, p. 137). O já citado massacre de Srebrenica, por exemplo, ocorre quando o ICTY já estava em funcionamento. De fato, a primeira acusação feita pelo tribunal ocorreu em novembro de 1994, mas seu primeiro julgamento iniciou-se apenas em maio de 1996. A primeira sentença veio em novembro do mesmo ano (ICTY, 1996).

Inicialmente, o tribunal tinha sua capacidade de ação restringida pela falta de recursos orçamentários, capacidade limitada de acesso à informação e principalmente, a ausência de força policial que lhe permitisse deter os acusados (CRYER et al., 2011, p. 125; TRBOVC \& PETROVIC, 2017, p. 137). Embora parte desses limitantes tenham se desfeito ao longo do tempo, a questão da capacidade de execução das decisões se tornou um problema real para o ICTY. As forças da OTAN na Bósnia e Herzegovina não tinham a obrigatoriedade de cumprir os mandados de busca e apreensão do Tribunal (GAETA, 1998, p. 174-181), e apesar do Acordo de Dayton ter estabelecido a cooperação dos países com o Tribunal Penal, isso não ocorreu de imediato. Dessa forma, o território da Croácia e da então República da Iugoslávia serviu de porto seguro para muitos acusados, graças a permissibilidade dos governantes. Apesar disso, o ICTY conseguiu, ao longo dos anos, se tornar mais efetivo no processo de detenção, muito graças à colaboração com o ICTY ter sido imposta como condicionalidade à possível entrada dos novos países em organizações internacionais como a União Europeia e a OTAN.

\section{Problemática}

\section{i. Objetivo Formal versus Papel Empírico}

Reconciliação é um termo usado no campo da justiça de transição para definir o processo no qual populações antes de lados opostos de um conflito conseguem voltar a conviver de maneira harmônica após o fim da violência. Embora tenha outras facetas, essa perspectiva, focada no tecido social e relações interpessoais, é a mais tratada pelos autores da área. A reconciliação varia em nível individual, comunal ou nacional e em intensidade. Isto é, alguns autores defendem que é necessária apenas a coexistência não violenta, enquanto outros afirmam que a aceitação e integração dos grupos constitui o conceito (STRUPINKIENÈ, 2017, p. 452-472). Independente dos detalhes da definição que se adota, a reconciliação é um processo essencial a sociedades que buscam superar grandes episódios de violência. No caso específico das guerras que ocorreram na exIugoslávia, foi entendido que a reconciliação deveria dizer respeito especificamente entre aqueles principais grupos étnicos envolvidos (EASTMOND, 2010, p. 5). Dessa forma, a busca pela paz no fim do conflito necessitava invariavelmente da criação de mecanismos que possibilitassem a ocorrência desse movimento de conjugação entre os grupos 
envolvidos na guerra.

Embora objetivo formal do ICTY seja processar crimes individuais, a resolução que o cria (Resolution 827) também cita a crença de que o tribunal poderia contribuir para a criação de paz na Iugoslávia, criando a noção de que o tribunal tem a função também de ser um agente de paz. Essa noção deriva da ideia de que a responsabilização individual poderia incentivar um movimento coletivo de compreensão do passado (CRYER et al., 2011, p. 108). Não só isso, mas o julgamento penal de indivíduos permitiria que a culpa fosse individualizada, de forma a evitar que comunidades inteiras fossem responsabilizadas pelas atrocidades cometidas, possibilitando a convivência entre elas. A admissão pública de responsabilidade, reconhecimento dos crimes e convergência em torno de uma só narrativa são elementos essenciais do processo de reconciliação em nível nacional (STRUPINKINÈ, 2017, p. 456) e a ocorrência de todos eles no cenário pósguerra da Iugoslávia envolvia, em algum grau, o ICTY (TRBOVC \& PETROVIC, 2017, p. 135-136). Dessa forma, há uma diferenciação clara entre o objetivo formal do tribunal e o papel que ele ocupa na prática.

Dessa forma, nota-se o papel essencial que o ICTY tomou na construção da paz na região, fenômeno que pode ser entendido como fruto de um processo de legalismo no pós-conflito. Isto é, existe um fortalecimento excessivo da noção de resolução de problemas por meios legais, acarretando um o foco praticamente único na "justiça jurídica" (SUBOTIC, 2012, p. 109), em prejuízo de outros mecanismos complementares de um processo de construção de paz, que deveriam ser igualmente essenciais. A existências desses mecanismos é entendida como necessária em um processo de reconciliação, embora praticamente não tenha ocorrido na região. Nenhum dos países estabelece com sucesso uma comissão da verdade efetiva e independente do ICTY (DEJAN, 2004; DRAGOVIC-SOSO, 2016, p. 293), por exemplo. No mesmo sentido, não ocorreu pedido de desculpas oficial por nenhuma parte, ou pagamento de reparações. Também não houve um esforço de reforma educacional no sentido de promover um ensino mais empático sobre o conflito (SUBOTIC, 2014, p. 177).

A corte adota essas expectativas ao inseri-las em seu discurso - o site oficial do tribunal, por exemplo, afirma que estabelecer os fatos sobre a guerra era uma de suas metas e no primeiro relatório anual após o início de suas atividades, o presidente do ICTY inclui a contribuição para a restauração da paz entre suas intenções (ICTY, 1994) -, assumindo para si esse papel, que é amplamente reforçado por atores da comunidade internacional (SUBOTIC, 2014, p. 181) e do campo acadêmico dedicado ao estudo da justiça de transição (TEITEL, 2005, p. 835-862).

É inteiramente plausível entender tais expectativas como exageradas e desproporcionais as reais capacidades e funções do tribunal, de forma que há um contraargumento possível e de relativa facilidade em questionar sua existência em primeiro lugar, porém essa adoção por parte da própria instituição permite que se meça a eficácia do tribunal não só como entidade jurídica e a partir de sua capacidade processual de julgamento, mas também como ator no processo de paz. Dessa maneira, torna-se não só possível, como necessário buscar julgar a capacidade do tribunal de atingir esses objetivos amplos e demasiado otimistas. 


\section{ii. Construção de Narrativa Única}

A construção de um relato histórico único, em particular, foi talvez a função mais importante do órgão para a construção da paz (SIMIC, 2016, p. 2). Isso porque a existência de narrativas diferentes acerca de um conflito impede a criação da união social que a reconciliação busca criar. Como visto na revisão histórica do conflito feita no início desse artigo, ao fim da guerra a visão dos grupos étnicos sobre os acontecimentos difere enormemente entre si. Assim, a capacidade de se criar uma narrativa comumente aceita era um ponto chave de todo o esforço pós-guerra.

Como coloca Backer, "tribunais julgaram as guerras iugoslavas e as narraram", em um processo que aproximava de maneira inédita as noções de justiça, direito, construção de paz e reconciliação $(2015$, p. 98). No entanto, a ideia de que o ICTY poderia criar uma narrativa sobre o conflito é falha por natureza, uma vez que se propõe julgar indivíduos. Absolver um indivíduo de uma acusação de qualquer crime implica apenas em negar a sua participação no evento - ou simplesmente a capacidade da promotoria de provar isso -, não o evento como um todo. Porém, dado o protagonismo da Corte, acabase por interpretar politicamente as decisões da mesma, de forma que o último é frequentemente assumido (BACKER, 2015, 104). Ou seja, construir narrativas sobre a situação geral baseada em casos específicos é inerentemente incoerente. Essa hipótese se comprova a partir de um número de casos ocorridos nos julgamentos do ICTY, dois dos quais serão expostos em breve.

Esse protagonismo é ainda mais potencializado pela lentidão e relutância dos países envolvidos de estabelecerem cortes domésticas para complementar o processo de justiça de transição. O Tribunal de Crimes de Guerra (WCC) só foi estabelecido na Sérvia em 2002, e similarmente, o órgão bósnio com mesmo objetivo foi fundado em 2005. Mesmo depois de estabelecidas, a existência desses organismos não implicou em sua eficiência, uma vez que os governos se mostram permanentemente oposto à sua atuação, ignorando-os ou exercendo sobre eles alto nível de controle, o que acaba por restringir e deslegitimar sua atuação perante o público e instituições de direitos humanos, mantendo o ICTY como único mecanismo jurídico reconhecido (SUBOTIC, 2014, p. 176).

Portanto, para atingir o papel que o tribunal assume, era essencial que ele fosse capaz de se desenvencilhar não só de qualquer parcialidade formal, como se provava nos casos de seus antecessores, mas também de qualquer percepção de parcialidade. Isso porque, para que ele pudesse alcançar os objetivos que havia assumido, era necessário que a população percebesse seus procedimentos como justos, de forma que estes pudessem moldar a narrativa oficial a ser adotada dali em diante. No entanto, é perceptível que ao longo da existência do ICTY a confiança das populações envolvidas acerca da arbitragem do tribunal se corrói, com inúmeras instâncias em que seus procedimentos são percebidos como favoráveis ou contrários a determinados grupos. Algumas instâncias emblemáticas desse fenômeno são exploradas a seguir com o objetivo de exemplificar

\footnotetext{
${ }^{5}$ No original: "tribunals both judged the Yugoslav wars and narrated them".
} 
esse processo.

\section{iii. Caso Ante Gotovina}

Esse caso é importante para a análise por dois motivos principais: a importância dele para a narrativa do conflito e o desenvolvimento dele no tribunal, que passou por uma reversão do resultado inicial. Ante Gotovina, um general croata, foi acusado em 2001 de promover a deportação forçada e o assassinato da população minoritária sérvia que vivia em território croata entre agosto e novembro de 1995. Na declaração inicial, liase que:

As forças croatas cometeram vários atos de assassinato, incêndio criminoso, pilhagem, assédio, terror e ameaça de danos físicos a pessoas e propriedades. Com esses atos, as forças croatas intimidaram e coagiram os sérvios Krajina a deixar suas vilas, aldeias e casas (ICTY, 2001, tradução nossa). ${ }^{6}$

A importância simbólica dessa acusação se deu por ela se referir aos eventos relacionados à Operação Storm. Essa operação foi uma ofensiva militar promovida pela Croácia, responsável por recuperar o território dominado por servos no país. A operação foi um dos fatores que possibilitou o fim da guerra e a assinatura dos acordos de Dayton, com a região se rendendo às forças croatas posteriormente ao evento (BACKER, 2015, p. 76), mas permaneceu sendo ponto de tensão entre os dois países.

Para os sérvios, os acontecimentos da operação Storm são um caso de limpeza étnica e uma das memórias mais dolorosas da guerra. Sua ocorrência foi perpetuada no entendimento coletivo como prova de que as minorias sérvias em outros territórios foram vítimas de violência, de forma que as ações das forças do país teriam ocorrido em sua defesa. Dessa forma, a operação é ponto importante da narrativa que apresenta os sérvios como vítimas, e não perpetradores, da violência (SUBOTIC, 2013, p. 306-326; TRBOV \& PETROVIC, 2017, p. 144). Sendo assim, a acusação e posterior sentença de Gotovina por esses acontecimentos foi entendido no país como uma confirmação e legitimação dessa visão (SUBOTIC, 2014, p. 172).

De maneira similar, a Operação Storm também ocupa um papel importante na construção de narrativa para a Croácia. No entanto, de maneira oposta, a visão deles sobre o evento é que ele constituiu um marco importante na guerra pela independência do país, mas que não houve tentativa de limpeza étnica pelas mãos das forças croatas. Na visão deles, o êxodo da população e tnicamente sérvia se deu por deslocamento voluntário ou incentivado por forças rebeldes da própria Sérvia (SUBOTIC, 2014, p. 171).

Dado a importância simbólica do caso para ambos os países e a construção de suas respectivas narrativas, é fácil entender a intensidade e a complexidade que o julgamento tomou. Após a acusação, houve uma forte oposição por parte da população croata frente

\footnotetext{
${ }^{6}$ No original: "Croatian forces committed numerous acts of killing, arson, looting, harassment, terror and threat of physical harm to person and property. By these acts, Croatian forces intimidated and coerced Krajina Serbs into leaving their villages, hamlets and homes".
} 
ao que eles consideravam uma ofensa à um momento emblemático da história do país. $\mathrm{E}$ embora não tenha formalmente se recusado a cooperar, o governo croata foi suspeitosamente lento em tomar qualquer ação para apreender o general, o que permitiu que ele evadisse as autoridades. Gotovina só foi capturado em 2005, e até lá as negociações pela entrada da Croácia na União Europeia chegaram a ser interrompidas devido a situação (SUBOTIC, 2009, p. 379).

Gotovina foi sentenciado pela câmara de julgamentos em abril de 2011, resultado que foi recebido por celebração e fúria na Sérvia e na Croácia, respectivamente. Porém, causa de uma reação ainda mais severa foi a decisão da câmara de apelações, pouco mais de um ano depois. A decisão reverteu por completo o julgamento inicial, afirmando que as evidências apresentadas não provavam as acusações (TRBOVC \& PETROVIC, 2017, p. 144; IRWIN, 2013). Embora essa decisão não negasse a existência de limpeza étnica, o sentimento dos sérvios era justamente esse. Manifestações públicas ocorreram em Belgrado, com alguns afirmando que o tribunal havia legitimado a limpeza étnica contra sérvios e políticos sérvios se colocaram em forte oposição à reversão da sentença.

$\mathrm{O}$ impacto do caso nos esforços de reconciliação foi sentido de forma imediata. $\mathrm{O}$ primeiro-ministro da Sérvia afirmou que o veredito coloca em risco os esforços de cooperação, expressando a repercussão com a população geral sérvia ao dizer que aos olhos deles, o ICTY havia comedido suicídio (RISTIC, 2012). Na mesma linha, o presidente foi mais longe e disse que colocaria um fim nos esforços reconciliatórios, encontrando a maneira perfeita para causar novos conflitos (B92, 2012).

Já na Croácia, a notícia foi recebida com festa pública no centro de Zagreb. Na visão croata, o resultado retirava qualquer dúvida sobre a legalidade e legitimidade do processo de independência do país, absolvendo-o da ligação com limpeza étnica. Um dos maiores jornais do país estampou em sua capa a notícia de Gotovina sob a manchete "Croácia é Inocente" (IRWIN, 2013), comprovando mais uma vez como utilizar processos individuais no esforço de estabelecer uma narrativa dominante não é estratégia perspicaz.

\section{iv. Caso Moncilo Perisic}

Em um caso similar ao de Ante Gotovina, o general do exército iugoslavo Moncilo Perisic também viu sua sentença ser revertida pela câmara de apelações do ICTY. Inicialmente condenado a 27 anos por crimes ligados à campanha militar de grupos sérvios contra civis croatas e bósnios, o general foi posteriormente absolvido sob o argumento de que não era possível comprovar sua participação nesses eventos. Assim como no exemplo anterior, esse resultado foi mobilizado pelas narrativas de cada grupo, com os sérvios comemorando-o, enquanto que na Bósnia ele causava um profundo sentimento de injustiça (SUBOTIC, 2014, p. 171). Perisic retornou a Belgrado em um avião do governo sérvio e discursou frente uma calorosa recepção do público, quando afirmou que havia defendido a "honra, dignidade e vida dos cidadãos" (B92 apud SUBOTIC, 2014, p. 175). 
A partir desses dois casos, observa-se que decisões jurídicas não contribuem, como o tribunal intencionava, para a reconciliação. Isso porque elas não são o suficiente para instaurar uma narrativa aceita por todos os lados. Invés disso, a decisão é manejada pelas narrativas já existentes, que colocam o ICTY como inimigo ou aliado dependendo de como a decisão as afeta. Logo, não são essas narrativas que perdem força com o público, e sim a organização, que passa a ser entendida como um ator parcial. Quando essas decisões, como nos casos apresentados, são fruto de uma apelação, o poder de construção de narrativa do Tribunal é mais ainda mais afetado. A reversão por completo do julgamento inicial, embora uma possibilidade prevista e completamente legal, permite que a população se frustre com o que ela percebe como contradições e "troca de lado" da corte, colocando em xeque a sua credibilidade (TRBOVC \& PETROVIC, 2017, p. 148). Explicar de maneira competente as razões para a diferença entre as sentenças para a população é extremamente difícil, pois ela tende a não se ater a detalhes técnicos do processo, limitando-se a enxergar apenas o resultado final. No entanto, mais do que a dificuldade, o ICTY parece não ter feito muito esforço para assumir a tarefa de explicar para a população as justificativas por trás de suas decisões (SUBOTIC, 2014, p. 178), o que possibilita um recebimento negativo delas.

\section{v. O Impacto na Situação Atual}

O movimento de acirramento de tensões durante a atividade do ICTY, que foi exposto por meio desses exemplos, é reforçado quando analisado o contexto nos países mais recentemente, anos após esses casos e o fim oficial do tribunal. Não há evidência concreta de que os julgamentos do ICTY tenham tido qualquer sucesso em induzir um reconhecimento dos grupos sobre seus papéis na guerra (TRBOVC \& PETROVIC, 2017, p. 148). Pelo contrário, Marko Milanovic, professor na University of Nottingham School of Law, publicou em 2016 um artigo no qual ele compila resultados de pesquisas comissionadas pelo Belgrade Center for Human Rights (BCHR), em parceria com a Organização para a Segurança e Cooperação na Europa (OSCE). As pesquisas foram feitas na Bósnia, na Croácia e na Sérvia entre 2011 e 2012 (MILANOVIC, 2016).

Nos três países, as opções negativas foram mais escolhidas do que as positivas. A pesquisa descobriu que de fato os resultados dos julgamentos são interpretados a partir de divisões étnicas. Ao conduzir entrevistas apenas no território sérvio, concluiu-se que menos de $20 \%$ dos que se identificavam como etnicamente sérvios afirmaram aceitar o julgamento de sérvios acusados de crimes de guerra e acreditar que ele foi feito com base nas evidências. Já na população etnicamente bósnia na Sérvia, esse número é de mais de $80 \%$. Em outra pergunta proposta na pesquisa, $74 \%$ dos sérvios afirmaram acreditar que eram eles as maiores vítimas da guerra. Similarmente, entre os bósnios $86 \%$ se nomearam para a mesma posição. Sobre Srebrenica, o episódio mais marcante das guerras, apenas $10 \%$ dos sérvios acreditam que aconteceu o que foi estabelecido pela corte. O restante se divide entre não acreditar que houve execuções, que houve, mas que seus números foram fortemente exagerados, não acreditar no acontecimento como um todo ou não sabe ou não querer responder (BCHR Surveys apud MILANOVIC, 2016). Resumindo a tendência identificada em todas os resultados das pesquisas, o autor afirma: 
As pesquisas demonstram uma forte relação entre a etnia dos entrevistados, sua percepção do preconceito do ICTY contra os membros de seu próprio grupo e sua (falta de) confiança no ICTY e em suas descobertas. Croatas étnicos e sérvios étnicos (seja na Sérvia, Kosovo, Croácia ou Bósnia) exibem altos níveis de desaprovação do ICTY (MILANOVIC, 2016, tradução nossa). ${ }^{7}$

Dessa forma, podemos identificar a partir desses achados que o ICTY não mudou a visão dos grupos sobre os acontecimentos. Ao contrário, a visão deles foi e permaneceu sendo responsável por moldar como eles enxergam o Tribunal. Sendo assim, o Tribunal não é entendido como uma autoridade no estabelecimento dos fatos, mas um ator parcial que pode se colocar contra ou a favor dos grupos. Se extingue qualquer chance de que a população tenha fé na capacidade de arbitragem neutra da Corte. Qualquer decisão contrária à narrativa defendida por um grupo será justificada então na suposta tendenciosidade da instituição.

Além de ser um impedimento à reconciliação, a crescente desconfiança da população para com o tribunal pode ser fonte de desequilíbrios internos, principalmente quando considerados a delicada democracia de países recém-saídos de um conflito. Como já citado anteriormente, um dos fatores mais importantes na garantia do sucesso da ICTY foi a pressão internacional para a cooperação dos países com o tribunal. Essa pressão pode tomar várias formas, coercitivas ou não, mas no caso em questão, ela se deu primordialmente pelo uso dos mecanismos de condicionalidade. Ao condicionar a entrada em organismos como a União Europeia ao sucesso do ICTY, a comunidade internacional cria uma forte pressão externa que levou os países, em especial a Croácia, a trabalhar com o tribunal. No entanto, essa pressão funciona num nível apenas institucional. Isso é, a população não é afetada por ela, de forma que a demanda por justiça e reconciliação não necessariamente se estende à população (SUBOTIC, 2009, p. 364-380).

Ao contrário, o crescente descontentamento com os rumos dos julgamentos cria uma baixa pressão doméstica por justiça, ou até mesmo uma pressão contrária. $\mathrm{O}$ somatório dessas duas variantes cria um cenário altamente arriscado para a estabilidade interna, representando um risco importante numa região ainda bastante dividida, que passa por um período de transição democrática. Além disso, isso faz com que também exista a possibilidade de que os benefícios oferecidos pela comunidade internacional simplesmente não sejam mais entendidos pelos governos como vantajosos, quando comparados com o possível risco político doméstico (SUBOTIC, 2009, p. 364-366).

É claro que todo esse cenário não pode ser atribuído inteiramente à falha do ICTY, uma vez que a reconciliação é um processo altamente complexo. Há outros inúmeros fatores que podem ter influenciado nesse contexto atual. No entanto, dado o já

\footnotetext{
${ }^{7}$ No original: "The surveys demonstrate a strong relationship between the respondents' ethnicity, their perception of the ICTY's bias against members of their own group, and their (lack of) trust in the ICTY and in its findings. Ethnic Croats and ethnic Serbs (whether in Serbia, Kosovo, Croatia, or Bosnia) exhibit strong levels of disapproval of the ICTY".
} 
comprovado protagonismo atribuído ao ICTY na marcha em direção ao convívio harmonioso e estabelecidos exemplos que provam a incapacidade de se garantir que seus resultados sigam nesse sentido, é plausível assumir que a tensão atual pode ser justificada, pelo menos em parte, por essa falha. A perpetuação das narrativas conflituosas e excludentes, definidas pelos marcadores étnicos que moldaram a guerra, em especial pode ser ligada à ineficiência do ICTY de cumprir a principal tarefa lhe dada: construir uma narrativa única.

\section{Conclusão}

O objetivo deste trabalho não é negar a importância do ICTY. Pelo contrário, reconhece-se a função essencial dele no processo de desenvolvimento do Direito Internacional Penal e sua influência nos mecanismos existentes hoje na comunidade internacional, principalmente o ICC. O ICTY foi um instrumento notável no desenvolvimento dos paradigmas que regem o direito. A criação da noção de accountability individual não necessariamente existiria da forma como a conhecemos hoje sem os acontecimentos e desdobramentos na ex-Iugoslávia. Não só isso, embora perca a confiança da população em sua arbitragem, o ICTY definitivamente consegue superar os erros de seus antepassados, e é um dos primeiros momentos em que promover a justiça em um cenário pós-conflito não implica na destruição total de um dos lados.

Também não se busca alegar o fracasso integral do órgão. Como mostrado, o papel que o tribunal assume é diferente de seu objetivo formal, que se limita a promover julgamentos penais aos indivíduos envolvidos na violência. Esse objetivo o ICTY comprova com números e dados que, pelo menos em algum nível, foi alcançado.

Além disso, vale reforçar novamente o fato de que o processo de reconciliação é extremamente multifacetado (STRUPINKIENÈ, 2017, p. 453-454), de forma que fazer qualquer julgamento sobre sua efetividade é altamente complexo. Dessa maneira, os possíveis resultados negativos apresentados no texto não implicam na falência total desse processo. Da mesma forma, se chegada a essa conclusão, não se deve creditá-la inteiramente aos erros do tribunal.

O que se concluiu, no entanto, é que o ICTY foi apostado como capaz de ser um ator protagonista nesse processo, e a sua falha em exercer com sucesso esse papel prejudica a reconciliação. O legado do Tribunal, suas decisões e processo são mobilizados de maneira seletiva e parcial para fortalecer as narrativas que já existiam antes de sua criação. Dessa forma, o ICTY acaba por se tornar um possível fator de acirramento das tensões narrativas que existem acerca dos acontecimentos da guerra. Ou seja, o Tribunal contribuiu justamente para aquilo que havia sido colocado como um de seus objetivos combater. Contribuir para a reconciliação da região a partir, principalmente, do estabelecimento de fatos e consequente construção de uma narrativa única é uma meta que o tribunal não alcança. 


\section{Referências Bibliográficas}

B92. Cas da svi Srbi izadu iz Haga (Time for all Serbs to leave the Hague), 29 nov. 2012. Disponível em: $<$ http://www.b92.net/info/vesti/index.php?yyyy=2012\&mm=11\&dd=29\&nav category=11\&nav $\mathrm{id}=664558>$. Acesso em 30 de nov. 2019.

Perisic: Presuda doprinos za Srbiju [Perisic: The verdict helps Serbia]. Disponível em:

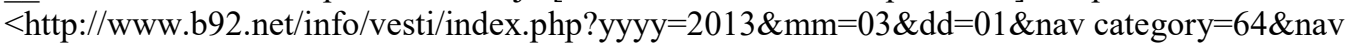
id=691229> Acesso em 30 de nov. 2019.

BACKER, Catherine. The Yugoslav Wars of the 1990s. Londres: Palgrave, 2015.

BENDERLY, Jill; KRAFT, Evan. Independent Slovenia: Origins, Movements, Prospects. Nova York: Palgrave Macmillan, 1994.

CRYER, Robert; FRIMAN, Hakan; ROBINSON, Darryn; WILMSHURST, Elizabeth. An Introduction to International Criminal Law and Procedure. $2^{\circ}$ ed. Cambridge: Cambridge University Press, 2010. DRAGOVIC-SOSO, Jasna. History of a Failure: Attempts to Create a National Truth and Reconciliation Commission for Bosnia and Herzegovina, 1997-2006. International Journal of Transitional Justice, v.10, n.2, 2016, p. 292-310.

EASTMOND, Marita. Reconciliation, Reconstruction, and Everyday Life in War-Torn Societies. Focaal, v. 57, 2010, p. 3-16.

FOLEY, Conor. UN Peacekeeping Operations and the Protection of Civilians: Saving Succeeding Generations. Cambridge: Cambridge University Press, 2017.

_. The Thin Blue Line: How Humanitarianism Went to War. Londres: Verso, 2015.

GAETA, Paola. Is NATO Authorized or Obliged to Arrest Persons Indicted by the International Criminal Tribunal for the Former Yugoslavia?. European Journal of International Law, v. 9, n. 1, 1998, p. 174181.

GLENNY, Misha. The Fall of Yugoslavia: The Third Balkan War. $3^{\circ}$ ed. rev. Londres: Penguin, 1996.

HAIDER, Huma. Imagining Coexistence: Striving for Sustainable Return, Reintegration and Reconciliation in Bosnia and Herzegovina. International Journal of Transitional Justice, v. 3, 2009, 91-113.

HAGAN, John. Justice in the Balkans: Prosecuting War Crimes in the Hague Tribunal. Chicago: University of Chicago Press, 2003.

HUMAN RIGHTS WATCH. Softly-Softly Approach on War Crimes Doesn't Help Democracy in Serbia. Human Rights Watch, 24 jun. 2004. Disponível em: <https://www.hrw.org/news/2004/06/24/softlysoftly-approach-war-crimes-doesnt-help-democracy-serbia>. Acesso em 01 nov. 2019.

ILIC, Dejan. The Yugoslav truth and reconciliation commission : Overcoming cognitive blocks. Eurozine, 23 Abril 2004. Disponível em: <https://www.eurozine.com/the-yugoslav-truth-andreconciliation-commission/>. Acesso em: 24 novembro 2021.

IRWIN, Rachel. Do overturned convictions undermine Hague Tribunal? Institute for War and Peace Reporting (IWPR). 20 March 2013 Disponível em; <http://iwpr.net/report-news/do-overturnedconvictions-undermine-hague-tribunal>. Acesso em 30 de nov. 2019.

ICTY About. Disponível em: <https://www.icty.org/en/about>. Acesso em 05 de dez. 2019.

_. About the ICTY: Achievements. Disponível em <www.icty.org/sid/324>. Acesso em 20 de nov. 
2019.

_. Key Figures of the Cases. Disponível em: $<$ https://www.icty.org/en/cases/key-figures-cases $>$. Acesso em 30 nov. 2019.

_. ICTY Timeline. Disponível em: <https://www.icty.org/node/8403>. Acesso em 05

_. Prosecutor v. Ante Gotovina, Case No. IT-01-45-I. 8 de Jun. 2001.

_. The First Annual Report of the ICTY. 29 August 1994. Disponível em:

<www.icty.org/x/file/About/Reports\%20and\%20Publications/AnnualReports/annual_report_1994_en.pdf

>. Acesso em 01 de dez. 2019.

INTERNATIONAL COURT OF JUSTICE. Case Concerning Application of the Convention on the Prevention and Punishment of the Crime of Genocide (Bosnia and Herzegovina v. Serbia and Montenegro). 16 fev. 2007. Disponível em: <https://www.icj-cij.org/public/files/case-related/91/09120070226-JUD-01-00-EN.pdf>. Acesso em 01 de dez. 2019.

MILANOVIC, Marko. The Impact of the ICTY on the Former Yugoslavia: An Anticipatory Postmortem. The American Journal of International Law, v. 110, n. 2, abr. 2016, p. 233-259.

NEIER, Aryer, War Crimes: Brutality, Genocide, Terror and the Struggle for Justice. New York: Times Books, 1998.

NOGUEIRA, João Pontes. A Guerra do Kosovo e a Desintegração da Iugoslávia: Notas sobre a (re)construção do Estado no fim do milênio. Revista Brasileira de Ciências Sociais, v. 15, n. 44, out. 2000, p. $143-160$.

POCAR, Fausto. Statute of the International Criminal Tribunal for the former Yugoslavia. Audiovisual Library of International Law. 2008. Disponível em: $<$ https://legal.un.org/avl/ha/icty/icty.html $>$. Acesso em 05 dez. 2019.

Potsdam Declaration. 1945. Disponível em: <https://www.ndl.go.jp/constitution/e/etc/c06.html>. Acesso em 05 de dez. 2019

RAMET, Sabrina R. The Three Yugoslavias: State-building and Legitimation, 1918-2005. Washington DC: Indiana University Press, 2006.

RISTIC, Marija. Belgrade protest over Croatian generals' acquittal. Balkan Insight. 2012. Disponível em: $<$ http://www.balkaninsight.com/en/article/belgrade-protest-over-generals-acquittal $>$. Acesso em 03 de dez. 2019.

SECURITY COUNCIL. Resolution 827. Disponível em:

$<$ https://www.icty.org/x/file/Legal\%20Library/Statute/statute_827_1993_en.pdf>; Acesso 05 dez. 2019.

_. Resolution 780. Disponível em: <http://unscr.com/en/resolutions/780>. Acesso em: 05 dez. 2019.

SIKKING, Kathlyn. The Justice Cascate: How Human Rights Prosecutions Are Changing World Politics. Nova York/Londres: W. W. Norton \& Company, 2011.

SIMIC, Goran. ICTY and the Question of Justice. Harvard Human Rights Journal, v. 29, 2016, p. 1 4.

STRUPINKIENÈ, Lina. What is reconciliation and are we there yet? Different types and levels of reconciliation: A case study of Bosnia and Herzegovina. Journal of Human Rights, v.16, n. 4, 2017, p.452-472.

SUBOTIC, Jelena. Legitimacy, Scope, and Conflicting Claimson the ICTY: In the Aftermath of Gotovina, Haradinaj and Perisic. Journal of Human Rights, v.13, 2014, p. 170-185. 
. Stories states tell: Identity, narrative, and human rights in the Balkans. Slavic Review, v. 72, n.2, 2013, p. 306-326.

. The Transformation of International Transitional Justice Advocacy. The International Journal of Transitional Justice, v. 6, 2012, p. 106-125.

The Paradox of International Justice Compliance. The International Journal of Transitional Justice, v.3, 2009, p.362-383.

TEITEL, Ruti. The law and politics of contemporary transitional justice. Cornell International Law Journal, v.38, n.3, 2005, p. 837-862.

TRBOVC, Jovana M.; PETROVIC, Vladimir. The Impact of the ICTY on Democratization in the Yugoslav Successor States. In: RAMET, Sabrina P.

UNITED NATIONS [Nações Unidas]. Updated Statue of the International Criminal Tribunal for the Former Yugoslavia, 2009. Disponível em:

$<$ https://www.icty.org/x/file/Legal\%20Library/Statute/statute_sept09_en.pdf $>$. Acesso em 05 dez. 2019.

Dayton Agreement. 30 de nov. 1995. Disponível em:

$<$ https://peacemaker.un.org/sites/peacemaker.un.org/files/BA_951121_DaytonAgreement.pdf $>$. Acesso em 05 dez. 2019.

_. The UN and the Situation in the Former Yugoslavia, UN Doc. DPI/1312/Rev.4, 1995, p. 65-66.

ZEJNULLAHI, Veton. Balkan Conflict, the Disintegration of Yugoslavia and the ICTY. Mediterranean Journal of Social Sciences, v.5, n.19, 2014. 